\title{
MICROFINANCE AS A TOOL FOR POVERTY REDUCTION: CASE OF WESTERN BALKAN COUNTRIES
}

In Happiness And Contemporary Society : Conference Proceedings Volume (Lviv, March, 20-21, 2021). Lviv: SPOLOM, 2021. P. 187-193. https://doi.org/10.31108/7.2021.43

ISBN 978-966-919-697-2 
https://doi.org/10.31108/7.2021.43

\section{MERA Nertil}

PhD in Finance, Lecturer at the Department of Banking and Finance, EPOKA University (Tirana, Albania)

TOZAJ Manjola

M.Sc. in Banking and Finance, EPOKA University (Tirana, Albania)

\section{MICROFINANCE AS A TOOL FOR POVERTY REDUCTION: CASE OF WESTERN BALKAN COUNTRIES}

Microfinance is of a vital importance to the unprivileged people especially in the developing countries. People with no means of sustaining themselves, rely on microfinance for a variety of services as a means for poverty reduction and increasing happiness. This study employs a Fixed Effects Model to analyze the impact of microfinance and some other macroeconomic factors on poverty reduction in Albania, Montenegro and Bosnia and Hercegovina. Empirical findings suggest that inflation does not play a role on the poverty reduction. On the other hand, total output (GDP) and microfinance (GLP) are found to be highly statistically significant in explaining the poverty reduction in the respective countries. Therefore, putting serious efforts on increasing GDP and supporting microfinance institutions may help the countries reduce the poverty level.

Keywords: Western Balkans, microfinance, GDP, poverty reduction, fixed effects model

\section{INTRODUCTION}

Poverty is a very crucial problem in the society, affecting many families around the world, and is one of the most severe forms of human deprivation. The issue of poverty is a global concern, and is one of the main factors affecting the quality of life and happiness. Most of the time, it is quantified through the per capita income indicators and the ability of individuals to meet basic living needs. Shastri (2009) suggests that the non-governmental organizations should reach out for the poor in areas like villages, where there is a lack of information. Furthermore, it recommends that the Microfinance Institutions (MFI's) should boost professional system into social microcredit system for the poor. Microfinance, more and more is being considered as a potentially useful instrument to offset the outcomes of the social and economic crisis in developed countries as well. Dawuda (2010) compares the operation of rural banks and financial NGOs in the specification of microfinance. The study uses a cross-sectional survey design and considers two microfinance institutions chosen to represent rural banks and financial NGOs. It shows that the financial performance of the rural bank is a lot more advanced than the financial NGO for the extent of outreach, portfolio quality, efficiency and productivity.

Eliminating poverty is an important goal for every country's policymakers, aiming at reducing poverty through the development of their poor economies. Microfinance is an important tool in providing credit for investment to rural and urban areas, that don't necessarily have access to the banking services in a sustainable way. 
This study focuses on Western Balkans region, distinguished by unstable financial systems and unsteady economies. Western Balkan countries face hardship in making progress in their economies in both, the short and long run. Comparing the Western Balkan countries based on their economic progress, Montenegro is the most well performing country with a higher GDP per capita than Serbia, Bosnia and Herzegovina, and Albania. ${ }^{1}$ Montenegro is dominated by the service sector where tourism is a rising industry. Regarding microfinance, Montenegro has around six microfinance institutions. On the other hand, Bosnia and Herzegovina has around 24 registered MFIs, out of which, 20 are nonprofit Micro Credit Finance institutions (MCFs) and 4 are for-profit Microcredit Organizations (MCOs). In Bosnia and Herzegovina microcredit thrived incredibly fast (Coskun, 2016). The countries selected for this study are respectively Albania, Montenegro and Bosnia and Herzegovina.

\section{LITERATURE REVIEW}

This section gives several assumptions and findings from earlier literatures and aims to provide theoretical foundation for the research. In the recent years, microfinance has been a significant component and valuable poverty reduction approach. Microfinance is an essential platform that can be used by the poor to increase their own possibilities for a break out from poverty (Matin et al., 2002). Many studies acknowledge an improved overall business environment through microfinance. Microenterprises can handle their financial risks better, grow their assets steadily and have a more efficient way of increasing their incomes. Furthermore, microfinance can also add to the progress of resource distribution, support of markets, and implementation of advance technology to encourage economic growth.

Lensink \& Pham (2012) studies the impact of microcredit on domestic self employment revenues in Vietnam using a fixed effects model. The findings show that microcredit does have a significant effect on increasing the self employment revenues. Furthermore, Jegede et al. (2011) supports the positive correlation between microfinance and poverty reduction. It utilizes chi-square test, F-test and T-test to study the relationship among microfinance loan disbursement and poverty reduction. The findings show a noteworthy difference among the people who use microfinance institutions and those who do not use. Another study analyzes the socio-economic effects of microcredit on women's wellbeing by applying a qualitative semi-structured interviewing method. The outcomes show that a significant portion of the underprivileged women have been liberated from profound poverty due to the possibilities presented by microcredit foundations (Hietalahati \& Linden, 2006). A positive impact of microfinance in poverty reduction in Bangladesh is shown by Khandker (2005) as well. The study uses household level data and employs fixed effects model to assess the cumulative effects of microfinance on consumption and poverty. Evidences show a significant impact of microfinance in an increased consumption. An overall improvement in local income reflected at those who were not part of microfinance was noticed as well. Moreover, Imai et al., (2012) confirms the encouraging effect of microcredit to reducing poverty at macro level by implying a cross-country panel data model. Additionally, Daher et al., (2014) brings a macroeconomic context to the subject through a dynamic panel data

\footnotetext{
${ }^{1}$ European Investment Bank (2016)
} 
analysis applied for 362 microfinance institutions from 73 countries in 5 regions from 2005 to 2011. The results illustrate that the effectiveness of microfinance institutions is greater in less developed economies. Differently, Khanam et al., (2018) studies the influence of microfinance on poverty improvement and tries to categorize the limitations of microfinance programs concerning poverty reduction. Variables such as cultivable land, earning per person, number of male persons, and the amount of loan are found to have a major impact on poverty easing.

Loca et al., (2014) evaluates the contribution of microfinance service to poverty reduction in Albania. It uses a combination of qualitative and quantitative approaches through questionaries. Findings affirmed that lending practices of microfinance institutions have an encouraging effect on business activities in rising employee earnings, job formation and enhancing turnover margin of enterprises. Muaharremi (2018), observes the overall improvement in the wellbeing of the microcredit borrowers. The outcomes show that microcredit initiates better living standards for borrowers by increasing the overall income level. In contrast, Coskun (2016) studies the efficiency of microfinance in Bosnia and Herzegovina showing that microfinance has deviated from the initial propose of fighting poverty. Other evidences from literature imply that MFI's tend to increase the interest rates and arrange repayments in short periods of time just so that they can amplify their financial sustainability. Consequently, this type of policy can limit the impact of micro-credit in diminishing poverty. Still, microcredit used for investments is expected to lead to increased living standards for borrowers through an increased income level.

\section{DATA AND METHODOLOGY}

The data used for this study are generated from MFIs' websites, Microfinance Information Exchange Market (MIX) and World Bank. Two MFIs per country are selected given the limited availability of data. The MFIs selected are respectively Montenegro Investment Credit Podgorica and Montecredit Podgorica for Montenegro, Mikrofin and Sunrise Mikrokreditna for Bosnia and Herzegovina, and Fed Invest and Fondi Besa for Albania. This study uses the final consumption of the families as an independent variable and as a proxy for the poverty measurement. Loan portfolio is used as an indicator for the performance of MFIs. The macroeconomic indicators include GDP (Gross Domestic Product) and GDP deflator. Using a panel data for the three countries, increases the number of observations and allows to increase the robustness of the findings.

\section{Model Specification}

The model employed in this study is a one-way fixed effects model as in (Khandker, 2005). It accounts for cross-section invariant factors. This model is found to be superior to POLS (Pooled Ordinary Least Squares) as it accounts also for heterogeneity. On the other hand, POLS disregards in full the panel structure of the data considering all observations as belonging to one big sample.

The linear multiple regression equation in this study takes the following form:

$$
\text { LGPOV }_{i t}=\beta_{0}+\beta_{1} * \text { GDPGrowth } h_{i t}+\beta_{2} * \text { GLP }+\beta_{3} * \text { GDPDeflator }_{i t}+\mu
$$

The model above is estimated using Heteroscedasticity-Autocorrelation standard errors thus accounting for two of the most common issues with time-series and panel 
data. It allows for obtaining consistent standard errors and accurate results out of hypothesis testing. Prior to interpreting the estimation output, checking for key assumptions is of fundamental importance as shown in the next part of this study.

\section{EMPIRICAL FINDINGS}

There are several assumptions that need to be verified before the final analysis as Unit Root Test, Normality in Residuals, Multicollinearity, Zero - Conditional Mean and Serial Correlation.

Stationarity Test:

Table 1: Unit Root Test Results

\begin{tabular}{|c|c|c|c|}
\hline Variable & Test Type & Test Statistic & Probability Value \\
\hline POV & Philips Perron & 66.3353 & 0.0000 \\
\hline GLP & Philips Perron & 38.0720 & 0.0000 \\
\hline GDP & Philips Perron & 61.8425 & 0.0000 \\
\hline GDP Deflator & Philips Perron & 52.1491 & 0.0000 \\
\hline
\end{tabular}

The test results of the time series show that the variables are stationary, since pvalue $<0.05$. It can be continued furthermore by running regression analysis.

\section{Normality of Residuals}

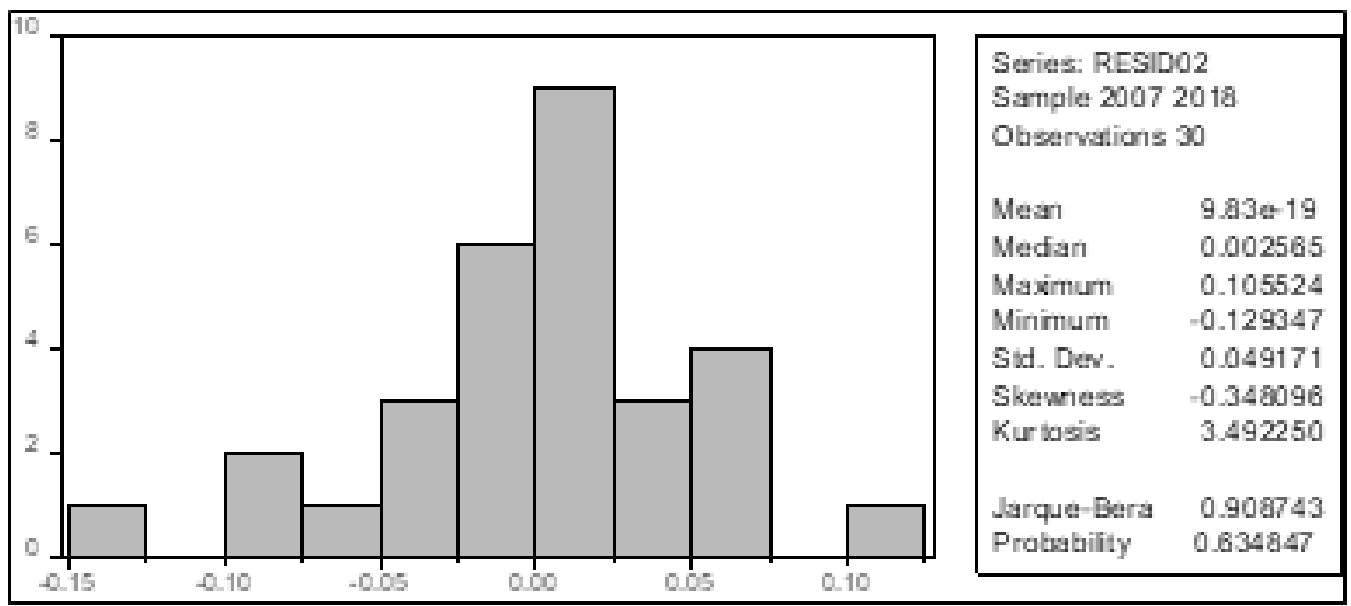

Figure 1: Histogram of Residuals Series.

As shown in Figure 1, at any conventional level, residuals are normally distributed. In this case, with a Probability value of $0.6>$ Alpha (0.05); it can be stated that residuals follow a normal distribution. 
Multicollinearity: When two or more independent variables are highly correlated this phenomenon is called multicollinearity (Wooldridge, 2012). There are several methods to test for multicollinearity such as Variance Inflation Factors (VIFs) method.

Table 2: Variance Inflation Factors

\begin{tabular}{|l|l|l|l|}
\hline Variable & Coefficient Variance & Uncentered VIFs & Centered VIFs \\
\hline GLP & 12.79565409 & 1.769859188 & 1.184498952 \\
\hline GDP_DEF & $3.97 \mathrm{E}+19$ & 3.048067805 & 1.683136765 \\
\hline GDP & $4.63 \mathrm{E}+19$ & 3.275032562 & 1.633851895 \\
\hline
\end{tabular}

VIF values exceeding 10 are indicators of serious multicollinearity problem. In this case, in both VIFs, un-centered or centered, the values are below 10 therefore there is no collinearity between variables.

Zero-Conditional Mean: As shown in the Table 3 below, the independent variables are free of the residual series. Referring to the values on the table, it can be stated that no key regressors' relevant for explaining $\mathrm{Y}$ are omitted from the model.

Table 3: Correlation Matrix ( $u$ and $X-s$ )

\begin{tabular}{|c|c|}
\hline & Residual Series \\
\hline DGDPDEF2 & $-1.60858 \mathrm{E}-16$ \\
\hline DLOGGLP2 & $1.08515 \mathrm{E}-16$ \\
\hline GDP2 & $4.78798 \mathrm{E}-17$ \\
\hline
\end{tabular}

Serial Correlation: Serial correlation or Autocorrelation happens when error terms are correlated (Wooldridge, 2012). The regression is estimated using heteroscedasticityautocorrelation consistent standard errors. The results in the table below show proof of no serial correlation in the residuals' series.

Table 4: Autocorrelation Results (residuals)

\begin{tabular}{|c|c|c|c|c|}
\hline Variable & Coefficient & Std. Error & t-Statistic & Prob. \\
\hline RESID01(-1) & -0.081526 & 0.164251 & -0.496351 & 0.624 \\
\hline C & 0.000177 & 0.000208 & 0.852619 & 0.402 \\
\hline
\end{tabular}

Estimation Output: The table below presents the final estimation output. As shown by the R-squared, 55\% of the variability in the dependent variable is explained via this model. The model is shown to be statistically significant at all conventional significance level (i.e. $\alpha=1,5,10 \%$ ). 


\begin{tabular}{lrrrr}
\hline Dependent Variable: LGPOV & & & & \\
Method: Panel Least Squares & & & & \\
White period standard errors \& covariance & (d.f. corrected) & & & \\
\hline Variable & Coefficient & Std. Error & t-Statistic & Prob. \\
GdpDeflator & -0.0020 & 0.0045 & -0.4324 & 0.6693 \\
GDPGrowth & $\mathbf{0 . 0 0 7 8}$ & $\mathbf{0 . 0 0 1 6}$ & $\mathbf{5 . 0 3 4 6}$ & $\mathbf{0 . 0 0 0 0}$ \\
GLP & $\mathbf{0 . 0 9 4 3}$ & $\mathbf{0 . 0 3 1 3}$ & $\mathbf{3 . 0 1 2 2}$ & $\mathbf{0 . 0 0 6 0}$ \\
C & -0.0078 & 0.0011 & -7.2118 & 0.0000 \\
\hline & $\mathbf{E f f e c t s ~ S p e c i f i c a t i o n ~}$ & & \\
Cross-section fixed (dummy variables) & & & & \\
R-squared & 0.55146 & & & \\
Adjusted R-squared & 0.45801 & & & \\
F-statistic & 5.90133 & & & \\
Prob(F-statistic) & 0.00108 & & & \\
\hline
\end{tabular}

The probability F-statistic shows that there is enough evidence in favor of the alternative and that we can reject the null hypothesis $\mathrm{H} 0$ : $\beta 1=\beta 2=\beta 3=0$. As shown by the results above, inflation (captured by GDP Deflator) is highly insignificant statistics-wise. These variable results to be irrelevant in explaining variability in $\mathrm{Y}$ in this case. On the other hand, the final output (GDP) and microfinance (GLP) seem to be highly significant in explaining the response variable. Finally, the higher the level of output produced within the county in one year and the higher the magnitude of microfinance, the higher the expenditures of individuals thus suggesting poverty reduction for the sample countries considered.

\section{CONCLUSIONS}

Microfinance is known as an economic instrument which promotes financial services such as savings, loans and other financial resources in small amounts to lowincome individuals and businesses that cannot afford these financial resources in other financial institutions. This study employs a Fixed Effects Model to analyze the impact of microfinance and some other macroeconomic factors on poverty reduction for Albania, Montenegro and Bosnia and Hercegovina. Empirical findings suggest that the countries on this study can help reduce poverty by putting serious efforts on increasing GDP and supporting microfinance institutions. This is in line with previous researchers who consider microfinance as a panacea to the economic distress faced by a considerable part of the population in developing countries. Some of the limitations of this study are regarding the availability of data which restricts the possibility of making a single country study. Overall, this research provides insightful findings with respect to microfinance and poverty as an issue of major importance for the countries as well as laying the foundations for future in-depth research. 


\section{REFERENCES}

1. Coskun, A. (2016). The Microfinance Tale: The Bright and Dark Sides of the Narrative Bosnia and Herzegovina Experiences. Regional Economic Development in the Balkan Region, 322-340.

2. Daher, L. \& Le Saout, E. (2014). Modeling the profitability of microfinance institutions: An application of the dynamic panel data methodology. 3rd International Symposium in Computational Economics and Finance (ISCEF) France.

3. Dawuda, M., A. (2010). A Comparative Study of Rural Banks and Financial NGOs in the Provision of Microfinance in the Yilo-Krobo District, Ghana. Vol 10.

4. Hietalahti, J., \& Linden, M. (2006). Socio-economic impacts of microfinance and repayment performance: A case study of the Small Enterprise Foundation, South Africa. Progress in Development Studies, 10, 201-210.

5. Imai, K. \& Azam, M., S. (2012). Does Microfinance Reduce Poverty in Bangladesh? New Evidence from Household Panel Data. Journal of Development Studies. Vol 48.

6. Jegede, A. \& Hamed, B. (2011). Impact of Microfinance on Poverty Alleviation in Nigeria: An Empirical Investigation.

7. Khanam, D., Mohiuddin, M., \& Hoque, A. (2018). Financing Mmicro-entrepreneurs for Poverty Alleviation: A Performance Analysis of Microfinance Services Offered by BRAC, ASA, and Proshika from Bangladesh. Journal of Global Entrepreneurship Research, 27.

8. Khandker, S. (2005). Microfinance and Poverty: Evidence Using Panel Data from Bangladesh. World Bank Economic Review, 19, 263-286.

9. Lensink, R \& Pham, T. (2012). The Impact of Microcredit on Self-Employment Profits in Vietnam. Economics of Transition, Vol. 20, Issue 1, 73-111.

10. Loca, S., \& Kola, F. (2014). Microfinance and Enterprises, Case of Albania.

11. Matin, I., Hulme, D., \& Rutherford, S. (2002). Finance for the Poor: From Microcredit to Micro-financial Services. Journal of International Development, 14(2), 273-294.

12. Muharremi, O., Luçi, E., Madani, F. \& Pelari, E. (2018). Evaluating the Impact of Microfinance at the Individual Level in Albania, Particularly in the Region of Vlora and Fier. Journal of Economics and Management Sciences, 1, p143.

13. Shastri, R. (2009). Microfinance and Poverty Reduction in India: A Comparative Study with Asian Countries. African Journal of Business Management, 3, 136-140.

14. Wooldridge, J., M. (2012). Introductory Econometrics: A Modern Approach. Mason, Ohio: South-Western Cengage Learning.

15. World Bank (2016). Financial Systems in the Western Balkans: Present and Future. Financial Sector Outlook. 